\title{
CARACTERÍSTICAS FÍSICO-QUÍMICAS DA POLPA DE UMBU (Spondias tuberosa Arruda Câmara) COMERCIAL: EFEITO DA CONCENTRAÇÃO
}

\section{PHYSICOCHEMICAL CHARACTERISTICS OF COMMERCIAL UMBU PULP (Spondias tuberosa Arruda Câmara): CONCENTRATION EFFECT}

\author{
Jaqueline Santos BASTOS ${ }^{[1]}$, Ernesto Acosta MARTINEZ ${ }^{[1]}$ e Silvia Maria Almeida de SOUZA ${ }^{[1]}$ \\ [1] Universidade Estadual de Feira de Santana, Av. Transnordestina, s/n - Novo Horizonte, 44036-900. Feira de Santana-BA, Brasil. \\ jaquelinesantos85@hotmail.comess_almeida@yahoo.com.br \\ *Autor para correspondência: ernesto.amartinez@yahoo.com.br \\ INFORMAÇÕES \\ RESUMO
}

Recebido em: $31 / 07 / 2015$

Aceito em: 12/10/2015

Publicado em: 28/03/2016

\section{Document Object Identifier}

$10.18067 / j b f s . v 3 i 1.48$

Editor: V. H. G. Sales

jbfs@ifap.edu.br

ID JBFS2015048

Avaliação a cega por pares

Prot. 0482015R01

Prot. $0482015 R 02$

Copyright: (C) 2016

JBFS all rights (BY NC SA)

O umbu é o fruto do umbuzeiro (Spondias tuberosa Arr. Cam.) que é uma árvore nativa do sertão brasileiro. O objetivo do presente trabalho foi avaliar as propriedades físico-químicas da polpa de umbu comercial e concentrada para ser utilizada como matéria-prima na produção de estruturado. A polpa comercial $(2,5 \mathrm{~kg})$ foi adquirida no comércio de Feira de Santana. A concentração da polpa em rotoevaporador a vácuo para aumentar o teor de sólidos solúveis de 8,5ㅂix para 15,5ㅂix foi realizada no Laboratório de Química de Alimentos da Universidade Estadual de Feira de Santana. Foi obtido após concentrar um rendimento de $41,12 \%$ em massa de polpa de fruta. $O$ processo de concentração não teve influência no valor nutricional da polpa de umbu. A polpa concentrada apresentou as seguintes propriedades $\mathrm{pH}(2,43)$, sólidos solúveis $\left(15,5^{\circ} \mathrm{Brix}\right)$, acidez $(3,11 \mathrm{~g}$ ácido cítrico/100 g), proteínas totais $(1,28 \%-\mathrm{m} / \mathrm{v})$, vitamina C $(4,36 \mathrm{mg} / 100 \mathrm{~g})$, açúcares redutores $(6,08 \%$ $\mathrm{m} / \mathrm{v})$, açúcares totais $(13,55 \%$ - m/v), açúcares não redutores $(7,46 \%-\mathrm{m} / \mathrm{v})$ e cinzas $(0,42 \%$ $\mathrm{m} / \mathrm{v}$ ). As características físico-químicas das polpas de umbu comercial apresentaram valores similares de $\mathrm{pH}$, teor de sólidos solúveis, acidez, proteínas e cinzas; maiores valores de açúcares redutores e não redutores e menor conteúdo de vitamina $C$ que as polpas reportadas na literatura. O processo de concentração produziu um aumento no teor de sólidos solúveis, proteínas, acidez, açúcares redutores e não redutores e no teor de cinzas. Porem houve uma diminuição no teor de vitamina $\mathrm{C}$ da polpa.

Palavras-chave: Polpa de umbu comercial; Concentração; Avaliação físico-química; estruturado

ABSTRACT: The umbu is the umbuzeiro fruit (Spondias tuberosa Arr. Cam.) which is a tree native of the Brazilian backlands. The aim of this work was to evaluate the physical and chemical properties of commercial and concentrated umbu pulp to be used as raw material in the production of structured. The commercial pulp ( $2.5 \mathrm{~kg})$ was acquired in the trade of Feira de Santana. The concentration of the evaporator route pulp vacuo to increase the soluble solids content of 8.5ㅂix to $15.5^{\circ}$ Brix It was held in the Food Chemistry Laboratory of the State University of Feira de Santana. It was obtained after concentrating a yield of $41.12 \%$ by mass of fruit pulp. The concentration process had no influence in the nutritional value of umbu pulp. The concentrated pulp had the following properties $\mathrm{pH}(2.43)$, soluble solids (15.5 $\left.{ }^{\circ} \mathrm{Brix}\right)$, acidity (3.11 g citric acid/100 g), total protein $(1.28 \%-\mathrm{w} / \mathrm{v})$, vitamin C $(4.36 \mathrm{mg} / 100 \mathrm{~g}-\mathrm{w} / \mathrm{v})$, reducing sugars $(6.08 \%$ $\mathrm{w} / \mathrm{v})$, total sugars $(13.55 \%-\mathrm{w} / \mathrm{v})$ non reducing sugars $(7.46 \%-\mathrm{w} / \mathrm{v})$ and ash $(0.42 \%-\mathrm{w} / \mathrm{v})$. The physicochemical characteristics of commercial umbu pulps had similar $\mathrm{pH}$, Total Soluble Solids, acidity, proteins and ashes; higher values of reducing sugars and non-reducing and a lower vitamin C content that the pulps reported in the literature. The concentration process produced an increase in Total Soluble Solids, proteins, acidity, reducing and non reducing sugars and ash content. However there was a decrease in vitamin C concentration of the pulp.

Keywords: commercial umbu pulp, concentration, physical-chemical evaluation, structured

Financiamento: Os autores reportam que houve suporte e auxílio financeiro por parte da Fundação de Amparo à Pesquisa do Estado da Bahia (FAPESB), processo 0015/2011

Conflito de interesse: Os autores declaram que não há conflito de interesse.

Como referir esse documento (ABNT):

BASTOS, J. S.; MARTINEZ, E.A.; SOUZA, S.M.A. de. Características físico-químicas da polpa de umbu (Spondias tuberosa Arruda Camara) comercial: Efeito da concentração. Journal of Bioenergy and Food Science, Macapá, v.3, n.1, p.11-16, jan./mar., 2016. DOI $10.18067 / \mathrm{jbfs} . v 3 i 1.48$ 


\section{INTRODUÇÃO}

O Brasil é o terceiro maior produtor, no ranking mundial, com uma colheita superior a 40 milhões de toneladas de frutas frescas desde 2004, com uma área de cultivo plantada de 2,14 milhões de hectares em 2012. ${ }^{1}$

O Nordeste brasileiro destaca-se como um grande produtor de frutos tropicais nativos e cultivados, em virtude das condições climáticas prevalecentes. O Estado da Bahia foi em 2012 o segundo maior produtor de frutas frescas do Brasil com um total de 4,748 milhões de toneladas e uma renda obtida de $\mathrm{R} \$ 2,175$ milhões. ${ }^{1} \mathrm{~A}$ fruticultura, nesta região, constitui-se em atividade econômica bastante promissora, devido ao sabor e aroma exótico de seus frutos e à sua enorme diversidade. O conhecimento do valor nutritivo dessas frutas assume importância considerável, pois a alimentação adequada assim como, a aplicação de métodos tecnológicos eficientes só se torna possível mediante o conhecimento do valor nutricional dos alimentos. ${ }^{2,3}$

O umbuzeiro (Spondias tuberosa Arruda Câmara) é uma arvore frutífera nativa da região do nordeste do Brasil que apresenta como principal característica a resistência à seca. Em 2012 foram coletadas $7.980 \mathrm{t}$ de umbu com a maior contribuição dos estados da Bahia (87\%), Pernambuco (5\%) e Rio Grande do Norte (3\%). ${ }^{4} \mathrm{O}$ restante da produção (4\%) é proveniente dos estados de Minas Gerais, Paraíba, Piauí Ceará e Alagoas.

O umbuzeiro, cujos frutos e raiz são ricos em vitamina $C$ e sais minerais, serve tanto para a alimentação do homem quanto para a de animais, e seu uso tem grande importância para as populações rurais do Semiárido, principalmente nos anos de seca. Seus frutos são vendidos pelos pequenos agricultores para consumo ao natural ou na forma de polpa, suco, refrescos, doce, umbuzada, licor, sorvetes, xarope de umbu, pasta concentrada, umbuzeitona, batida e umbu cristalizado. $^{5}$

Segundo a Instrução Normativa no 01, de 07 de janeiro de 2000, polpa de fruta é definida como sendo o produto não fermentado, não concentrado, não diluído, obtido de frutos polposos, através de processo tecnológico adequado, com um teor mínimo de sólidos totais, proveniente da parte comestível do fruto, devendo ser obtida a partir de frutas frescas, sãs e maduras, seguindo características físico-químicas e organolépticas do próprio fruto. ${ }^{6}$

A evaporação consiste em concentrar os alimentos líquidos por ebulição e o emprego de temperaturas baixas diminui as mudanças nas características sensoriais tais como coloração e perdas de aroma no produto. O principal objetivo da evaporação é aumentar a concentração de sólidos totais para reduzir a atividade de água (Aw), contribuindo assim para a conservação por maior período de tempo pela inibição do crescimento microbiano. $^{7}$

Dentre as técnicas de processamento, a estruturação de polpa de frutas representa uma inovação na área de alimentos, com resultados bastante promissores. ${ }^{8}$ Alimento estruturado ou designed food ou engineered food, são delineados de acordo com um planejamento, geralmente empregando-se matérias-primas de baixo custo, oriundas de frutas que se encontram fora de classificação para comercialização in natura ou excedentes de produção durante o período de safra, em muitos casos, utilizando-se hidrocolóides. $^{9}$ O uso de polpas concentradas implica na diminuição de sacarose usada para atingir a concentração de sólidos solúveis de $50^{\circ}$ Brix na formulação dos estruturados. ${ }^{10}$

Este trabalho teve como objetivo realizar a concentração da polpa de umbu comercial e analisar as propriedades físico-químicas das polpas comercial e concentrada.

\section{MATERIAL E MÉTODOS}

\section{a) Matéria-prima}

Foram coletadas $2,5 \mathrm{~kg}$ de polpa de umbu comercial congeladas de uma determinada marca em lotes diferentes, adquiridas em supermercados de Feira de Santana-BA (Brasil), no período de 11 a 22 de agosto de 2014.

As amostras foram transportadas em caixa de isopor até o Laboratório de Processamento de Alimentos da Universidade Estadual de Feira de Santana, onde foram armazenadas em Freezer a temperatura de $\left(-10^{\circ} \mathrm{C}\right)$ para posteriores análises.

Antes de concentrar e realizar as análises físico-químicas das polpas, as amostras foram descongeladas nas embalagens originais do produto, em geladeira $\left(2-5^{\circ} \mathrm{C}\right)$ por 20 horas. Em 
seguida, as amostras foram homogeneizadas e acondicionadas em sacos de polietileno e deixadas a temperatura ambiente. Posteriormente, as concentrações da polpa foram realizadas em rotoevaporador (Fisatom, mod. 802) nas condições de temperatura do banho de $50-55^{\circ} \mathrm{C}$, rotação de $120 \pm 5 \mathrm{rpm}$ e vácuo de $700 \mathrm{mmHg}$.

\section{b) Análises físico-químicas}

As análises físico-químicas das polpas comercial e concentrada foram realizadas em triplicata conforme descritos a seguir.

\section{c) Determinação de $\mathrm{pH}$}

$\mathrm{O} \mathrm{pH}$ foi determinado pelo método potenciométrico utilizando-se um pHmetro (PHS 3B Labermeter, Model PH2) com calibração feita em solução tampão de $\mathrm{pH} 4,0$ e 7,0 , a $20^{\circ} \mathrm{C} .{ }^{11}$

\section{d) Sólidos solúveis ( ${ }^{\circ}$ Brix)}

A leitura dos sólidos solúveis totais foi realizada através de um refratômetro portátil (LAMBDA, mod. WYT-4), colocando duas (2) gotas da polpa filtrada em algodão, na temperatura de $26^{\circ} \mathrm{C} .{ }^{11}$

\section{e) Acidez total titulável}

A acidez total em ácido cítrico foi obtida pela técnica de acidez titulável em ácido orgânico, com $\mathrm{NaOH} 0,1 \mathrm{~N}$ e utilizando a fenolftaleína como indicador conforme estabelecido Instituto Adolfo Lutz. $^{11}$ Os resultados foram expressos em porcentagem de ácido cítrico.

\section{f) Proteína total}

A análise de proteína foi realizada segundo o método de Kjeldahl conforme estabelecido pelo Instituto Adolfo Lutz. ${ }^{11}$ Os resultados foram expressos em percentagem mássica $(\mathrm{m} / \mathrm{m})$.

\section{g) Vitamina $C$}

A vitamina $C$ foi analisada através do método com iodato de potássio. Titulou-se com solução de iodato de potássio $0,02 \mathrm{M}$ até coloração azul. ${ }^{11} \mathrm{Os}$ resultados foram expressos em $(\mathrm{mg} / 100 \mathrm{~g})$.

\section{h) Açúcares redutores}

A determinação de açúcares redutores pelo método de Somogyi-Nelson é baseada nas propriedades redutoras dos açúcares, pela reação da hidroxila hemiacetálica dos monossacarídeos. Foi realizada a leitura da absorbância em espectrofotômetro em $540 \mathrm{~nm} \cdot{ }^{12}$ Os resultados foram expressos em percentagem $(\mathrm{m} / \mathrm{v})$.

\section{i) Açúcares totais}

Foi utilizado o método de Dubois et al. ${ }^{13}$, que se baseia na determinação de açúcares simples, polissacarídeos e seus derivados havendo a desidratação dos mesmos pelo ácido sulfúrico, sendo que o fenol na presença do ácido é usado para microdeterminação calorimétrica quantitativa de açúcares e seus derivados. Os teores de açúcares totais foram determinados por espectrofotometria a um comprimento de onda de $490 \mathrm{~nm}$ utilizando-se uma curva padrão de glicose. Os resultados foram expressos em percentagem $(\mathrm{m} / \mathrm{v})$.

\section{j) Açúcares não redutores}

Foram obtidos pela diferença quantitativa das análises de açúcares redutores e açúcares totais. Os resultados foram expressos em percentagem $(\mathrm{m} / \mathrm{v})$.

\section{k) Cinzas}

As cinzas foram determinadas com base na carbonização da amostra, sendo esta submetida à incineração, em mufla à temperatura de $550^{\circ} \mathrm{C}$ por aproximadamente $4 \mathrm{~h}$. A metodologia utilizada foi de acordo com o Instituto Adolfo Lutz. ${ }^{11}$ Os resultados foram expressos em porcentagem $(\mathrm{m} / \mathrm{m})$.

\section{RESULTADOS E DISCUSSÃO}

A etapa de concentração da polpa comercial $(2,5 \mathrm{~kg})$ obteve um rendimento de $41,12 \%$, valor equivalente a $1,03 \mathrm{~kg}$ de polpa, depois de retirado $45,64 \%$ de água contida na polpa comercial de umbu. $O$ processo foi realizado para elevar o teor de sólidos solúveis ( ${ }^{\circ}$ Brix) para garantir o uso de menor concentração de sacarose na formulação de estruturado de fruta e ter maior controle do processo.

As características físico-químicas da polpa comercial e concentrada, bem como de valores reportados na literatura são apresentados na Tabela 1. 
Tabela 1: Características físico-químicas das polpas de umbu (S. tuberosa, Arruda Camara) comercial e concentrada e valores reportados na literatura.

Table 1: Physical-chemical characteristics of the commercial and concentrated pulps umbu (S. tuberosa, Arruda Camara) and values reported in the literature.

\begin{tabular}{lcccccc}
\hline \multicolumn{1}{c}{ Propriedades } & $\begin{array}{c}\text { Polpa } \\
\text { comercial }\end{array}$ & $\begin{array}{c}\text { Polpa comercial } \\
\text { concentrada }\end{array}$ & $\begin{array}{c}\text { Bispo } \\
(1989)\end{array}$ & $\begin{array}{c}\text { Mattietto } \\
(2005)\end{array}$ & $\begin{array}{c}\text { Ushikubo } \\
(2006)\end{array}$ & $\begin{array}{c}\text { Oliveira et al. } \\
(2013)\end{array}$ \\
\hline $\mathrm{pH}$ & 2,42 & 2,43 & 2,45 & 2,75 & 1,70 & - \\
Sólidos solúveis ( ${ }^{\circ}$ Brix) & 8,50 & 15,50 & - & 9,59 & 9,40 & 10,10 \\
Proteínas totais (\%) & 0,68 & 1,28 & 0,52 & 0,75 & 0,58 & - \\
Acidez (ac. cítrico/100 g) & 1,88 & 3,11 & 1,23 & 1,39 & 1,95 & 0,79 \\
Vitamina C (mg/100 g) & 5,47 & 3,36 & 9,61 & 23,83 & 5,40 & 16,73 \\
Açúcares redutores (\%) & 4,96 & 6,08 & 6,07 & 3,63 & 3,22 & - \\
Açúcares não redut.(\%) & 3,56 & 7,46 & 1,88 & 1,30 & 1,89 & - \\
Açúcares totais (\%) & 8,52 & 13,55 & 7,95 & 4,93 & 5,11 & - \\
Cinzas (\%) & 0,37 & 0,42 & 0,33 & 0,40 & 0,40 & - \\
\hline
\end{tabular}

O processo de concentração não teve influência sobre o valor de $\mathrm{pH}$ da polpa tendo valores $(2,43)$ similares ao reportado por Bispo ${ }^{14}$. Polpas com maior $(2,75)$ e menor $(1,70)$ valores de $\mathrm{pH}$ foram verificadas por Mattietto ${ }^{15}$ e Ushikubo ${ }^{16}$, respectivamente (Tabela 1 ).

O teor de sólidos solúveis aumentou em 1,82 vezes após a etapa de concentração atingindo um valor de $15,5^{\circ}$ Brix. Polpas de umbu in natura com valores superiores de sólidos solúveis $(9,4$ a 10,1$)$ foram reportados em trabalhos anteriores (Tabela 1). O menor valor de sólidos solúveis na polpa comercial poderia estar relacionado com a adição eventual de água e pelo uso de aditivos e conservantes durante o processamento da polpa industrial para garantir maior tempo de vida de prateleira assim como devido a diferentes regiões, pontos de colheita e graus de maturação das frutas. ${ }^{6,17,18}$

Foi observado um aumento significativo (50\%) no teor de proteínas da polpa comercial após o processo de concentração. Contudo, este aumento de proteínas, foram inferiores aos reportados na literatura foram inferiores de $75 \%$ e de 59\%, respectivamente ao conteúdo desses componentes na polpa comercial e concentrada. $O$ conteúdo de proteínas, e de outras características centesimais, pode ser influenciado pelo ambiente pré-colheita, como: clima, temperatura e influencias do cultivo como o tipo de solo, suprimento de água e nutrientes, sendo fatores de influência na composição química encontrada nos frutos. ${ }^{19}$

Verificou-se na polpa comercial e concentrada um aumento expressivo (40\%) na acidez, expressada em ácido cítrico. Contudo, os valores de acidez foram inferiores de $37 \%$ a $75 \%$ ao conteúdo desses componentes na polpa comercial concentrada. Essa diferença pode ser explicada pelo processo de congelamento lento aplicado, o que ocasionou maior saída para o suco celular de ácidos orgânicos presentes, aumentando a acidez. ${ }^{20}$ Por outro lado, a variação desses valores de acidez pode ser devido às diferenças no estádio de maturação dos frutos, região e processamento. $^{21}$

A concentração de vitamina $C$ diminuiu em $20,3 \%$ após a concentração indicando que não houve degradação durante o processo de concentração (Tabela 1). Os teores de vitamina C da polpa comercial e concentrada são consideravelmente inferiores aos reportados na literatura. Isso pode ser devido às diferenças de processamento a citar: o fato dos frutos da polpa comercial ter naturalmente menor concentração de vitamina $C$ que os frutos utilizados nos estudos reportados na literatura, ${ }^{14,15,22}$ ou por uma degradação mais intensa da vitamina com o período de estocagem, o contato com o oxigênio atmosférico ou com a ação da luz. ${ }^{23}$

O teor de açúcares totais aumentou 1,59 vezes depois da concentração da polpa. Entretanto, 
foi constatado um aumento maior na concentração de açúcares não redutores (2,09 vezes) em comparação aos açúcares redutores (1,22 vezes). Todas as polpas possuem maior conteúdo de açúcares redutores $(3,22$ a $6,70 \%)$ que de açúcares não redutores $(1,30$ a 3,56\%) sendo que a polpa comercial teve a maior concentração de açúcares não redutores. As diferenças podem ser devido ao grau de maturidade dos frutos coletados para o preparo da polpa comercial e dos frutos utilizados nos estudos de referência. Um elevado grau de maturidade resulta no aumento dos teores de açúcares porque as carboidrases presentes nos frutos vão degradando os polissacarídeos, convertendo-os em monossacarídeos e dissacarídeos, entre outros. ${ }^{24}$

Com relação ao teor de cinzas, verificou-se um aumento de $0,37 \%$ até $0,43 \%$ após a concentração da polpa (Tabela 1). Resultados similares foram reportados na literatura para polpas in natura. ${ }^{14-16} \mathrm{O}$ teor de cinzas depende do tipo de solo e da composição do mesmo. ${ }^{25,26}$

A polpa de umbu comercial concentrada apresentou valores similares de $\mathrm{pH}$ e cinzas; maiores valores de sólidos solúveis, proteínas, acidez, açúcares redutores e não redutores e menor conteúdo de vitamina $\mathrm{C}$.

\section{CONCLUSÃO}

A concentração, em baixa temperatura, mostrou ser eficiente sendo possível obter uma polpa concentrada de umbu sem alterar suas propriedades físico-químicas.

\section{AGRADECIMENTOS}

À FABESB pelo apoio financeiro para a realização do trabalho.

À Universidade Estadual de Feira de Santana pelo apoio à pesquisa.

\section{CONTRIBUIÇÃO DOS AUTORES}

1 - Planejamento e condução do experimento; elaboração e revisão final do artigo.

Jaqueline Santos Bastos

Dr. Ernesto Acosta Martinez

Dra. Sílvia Maria Almeida de Souza

\section{REFERÊNCIAS}

[1]. SANTOS, C.E.; KIST, B.B.; CARVALHO, C.; REETZ, E.R.; DRUM, M. Anuário brasileiro da fruticultura. Santa Cruz do Sul: Gazeta Santa Cruz do Sul-RS, 136 p.: il. 2013.

[2]. SABLANI, S.S. Drying of fruits and vegetables: retention of nutritional/functional quality. Drying Technology, v.24, n.2, p.123-135, 2006.

[3]. SILVA, M.R.; LACERDA, B.C.L.; SANTOS, G.G.; MARTINS, D.M.O. Caracterização química de frutos nativos do cerrado. Ciência Rural, v.38, n.6, p.1790-1793, 2008.

[4]. SOARES, F.M.S. Companhia Nacional de Abastecimento. Ministério da Agricultura, Pecuária e Abastecimento. UMBU (fruto). Conab. Agosto, 2014.

[5]. COSTA, F.R.B.; SILVA, M.M.A.; ARAÚJO, V.S. Uso sustentável do umbuzeiro: estratégia de convivência com o semiárido. Campina Grande: INSA, 15p.: il. 2015.

[6]. BRASIL, Ministério da Agricultura e do Abastecimento, Instrução normativa no 1, de 7 de janeiro de 2000. Diário Oficial da União, Brasília-DF, 10 de jan. de 2000.
[7]. ORDÓÑEZ, J.A.P.; RODRÍGUEZ, M.I.C.; ÁLVEREZ, L.F.; SANZ, M.L.G.; MINGUILLÓN, G.D.G.F.; PERALES, L. L. H.; CORTECERO, M. D. S. Tecnologia de Alimentos: Componentes dos Alimentos e Processos. Porto Alegre: Artmed, v.1, p.203-204, 2005.

[8]. CARVALHO, A.V.; MATTIETTO, R.A.; VASCONCELOS, M.A.M. Aproveitamento da casca do bacuri para fabricação de um novo produto. Comunicado Técnico 209, Embrapa. Belém- PA, Setembro, 2008.

[9]. GRIZOTTO, R.K.; BRUNS, R.E.; AGUIRRE, J.M.; BATISTA, G. Otimização via metodologia de superfície de respostas dos parâmetros tecnológicos para produção de fruta estruturada e desidratada a partir de polpa concentrada de mamão. Ciência e Tecnologia de Alimentos, v. 25, n.1, p. 158-164, 2005.

[10]. LIMA, F.M.; MARTINEZ, E.A.; SOUZA, S.M.A.; SILVA, C.M.R.; BATISTA, Y.C. Aproveitamento do pedúnculo do caju para elaboração de fruta estruturada. Magistra, v.26, III CBPH, p.203-207, set., 2014. 
[11]. INSTITUTO ADOLFO LUTZ. Normas analíticas do Instituto Adolfo Lutz. v.1: Métodos químicos e físicos para análises de alimentos. 3. ed. São Paulo: IMESP, 2005.

[12]. NELSON, N. A photometric adaptation of Somogy method for the determination of glucose. The Journal of Biological Chemistry, v. 153, p.375-80, 1944.

[13]. DUBOIS, M.; GILLES, K.A.; HAMILTON, J.K.; REBERS, P.A.; SMITH, F. Colorimetric method for determination of sugars and related substances. Analytical Chemistry, v. 28, p. 350-356, 1956.

[14]. BISPO, E.S. Estudo de produtos industrializáveis do umbu (Spondias tuberosa, Arr. Câmara). 1989. Dissertação (Mestrado em Tecnologia de Alimentos) - Universidade Federal do Ceará, Fortaleza.

[15]. MATTIETTO, R.A. Estudo tecnológico de um néctar misto de cajá (Spondias lútea L.) e umbu (Spondias tuberosa, Arruda Câmara). 2005. 299 f. Tese (Doutorado) - Universidade Estadual de Campinas, Campinas, 2005.

[16]. USHIKUBO, F.Y. Efeito do tratamento enzimático, da velocidade tangencial e da pressão transmembrana na microfiltração da polpa diluída de umbu (Spondias tuberosa Arr. Cam). 2006. 117 p. Dissertação (Mestrado em Engenharia de Alimentos) - Universidade Estadual de Campinas, Campinas, 2006.

[17]. BUENO, S.M.; LOPES, M.R.V.; GRACIANO, R.A.S.; FERNANDES, E.C.B.; GARCIA-CRUZ, C.H. Avaliação da qualidade das polpas de frutas congeladas. Revista do Instituto Adolfo Lutz, v.62, n.2, p.121-126, 2002.

[18]. TOlentinO, V.R.; GOMES, A. Processamento de vegetais: Frutas/Polpa congelada. Niterói: Programa Rio Rural, 2008.
[19]. FENNEMA, O.R. Química dos alimentos. 4 ed. Zaragoza: Acribia, 2010. p.19-110.

[20]. CALEGANO, J.M.; PEZZI, E.; BENDER, R.J. Utilização de atmosfera modificada na conservação de morangos em pós-colheita. Pesquisa Agropecuária Brasileira, v.37, n.8, p.1049-1055, 2002.

[21]. GOMES, A.P.E.; SILVA, K.E.; RADEKE, S.M.; OSHIRO, A.M. Caracterização física e química de kiwi in natura e polpa provenientes da comercialização de Dourados - MS. Revista de Ciências Exatas e da Terra UNIGRAN, v.1, n.1, p.1-8, 2012.

[22]. OLIVEIRA, C.F.P.; SOUZA, S.M.A.; MARTINEZ, E. A.; GUANAIS, A. L. R.; SILVA, C. M. R. Study of the umbu (Spondias tuberosa Arruda Câmara) osmotic dehydration process. Semina: Ciências Agrárias, Londrina, v.34, n.2, p.727-738, 2013.

[23]. OYETADE, O.A.; OYELEKE, G.O.; ADEGOKE, B.M.; AKINTUNDE, A.O. Stability Studies on Ascorbic Acid (Vitamin C) From Different Sources. IOSR Journal of Applied Chemistry, v.2, n.4, p.20-24, 2012.

[24]. ChitARRA, M.I.F.; ChItARRA, A.B. Pós-colheita de frutas e hortaliças: fisiologia e manuseio. Lavras: UFLA, 2005. p. 783.

[25]. BURVALL, J. Influence of harvest time and soil type on fuel quality in reed canary grass (Phalaris arundinacea L.). Biomass and Bioenergy, v.12, n.3, p.149-154, 1997.

[26]. KHAN, A.A.; SAJID, M.; RAD, A. Tomato fruit quality as affected by different sources of phosphorus. Pakistan Journal of Nutrition, v.13, n.12, p.692-699, 2014. 